\title{
Removing the effect of striations in n-type silicon solar cells
}

\author{
G. Coletti ${ }^{\mathrm{a}, *, 1}$, P. Manshanden ${ }^{\mathrm{a}, 1}$, S. Bernardini ${ }^{\mathrm{a}}$, P.C.P. Bronsveld ${ }^{\mathrm{a}}$, A. Gutjahr ${ }^{\mathrm{a}}, \mathrm{Z} . \mathrm{Hu}^{\mathrm{b}}, \mathrm{G}^{\mathrm{L}} \mathrm{Li}^{\mathrm{b}}$ \\ a ECN Solar Energy, PO Box 1, NL-1755 ZG Petten, The Netherlands \\ b Yingli Energy (China) Co., Ltd., 3399 Chaoyang North Street, Boading, China
}

\section{A R T I C L E I N F O}

\section{Article history:}

Received 11 December 2013

Accepted 5 June 2014

Available online 23 July 2014

\section{Keywords:}

Striations

n-type

Defects

Annealing

Solar cells

Czochralski

\begin{abstract}
A B S T R A C T
Several industrial n-type Czochralski silicon ingots were analysed on wafer and cell levels with ECN's bifacial n-type solar cell process. In some of the ingots, the solar cell performance in the very top drop of about $1 \%$ absolute with respect to cell from the middle part of the ingot. These cells show typical ring shaped pattern. After receiving a post-process anneal treatment at $200{ }^{\circ} \mathrm{C}$, the efficiency nearly completly recover. We demonstrated that the improvement is due to bulk lifetime enhancement. The recovery is stable in storage conditions, under illumination and high temperature treatments up to $600{ }^{\circ} \mathrm{C}$. The same effect cannot be reproduced in p-type $\mathrm{Cz}$ silicon solar cells with similar ring shaped patterns. This indicates that the defects responsible for lifetime and efficiency degradation in wafers affected by ring patterns differ in n-type and p-type.
\end{abstract}

(c) 2014 Elsevier B.V. All rights reserved.

\section{Introduction}

Currently n-type crystalline silicon solar cells and modules are manufactured in mass production. In 2014 it is predicted to account of $6 \%$ of the total PV module production (49.7GW) [1] and according to the last edition of the International Technology Roadmap for Photovoltaic (ITRPV) the n-type share will grow to more than $30 \%$ in 2023 [2].

The background reasons for this trend rely on the specific characteristics of n-type silicon. Indeed, the lifetime of n-type wafers is generally much higher than p-type wafers for the absence of boron-oxygen (B-O) complex responsible for light induced degradation [3,4] and for the smaller recombination strength of metal impurities like Fe $[5,6]$. Although implementation of Dash's process has removed the most severe effects of dislocations [7], Cz crystals are still not defect-free [8]. While p-type ingots are dominated by $\mathrm{B}-\mathrm{O}$ complexes and impurities, the general higher lifetime in n-type cause other defects, like intrinsic defects, dislocations, etc., to become relevants. In particular very detrimental for the solar cell performance is the so called P-band ring which coincides with a band of grown-in oxide precipitates. These condense in stacking fault after a rapid wet oxidation which release interstitials under the oxide surface forming the so-called OISF ring. A review of this defect and their characterization has been given recently by $\mathrm{Hu}$ in [9]. This P-band is responsible for ring-shape or

\footnotetext{
* Corresponding author.

E-mail address: coletti@ecn.nl (G. Coletti).

${ }^{1}$ Authors with equal contributions.
}

disk regions of very low lifetime, affecting dramatically the solar cell performance [10]. Fortunately experienced crystal growers and optimized pullers can modify the position of the OISF-ring (P-band), which is triggered by the $V / G$ critical ratio $[11,12]$, pushing this defect region outside the wafering region of the crystals and, therefore, improving the ingot yield. In addition to the P-band, as the crystal grows, helical growth geometries are produced as consequence of the rotation of seed and crucible. Indeed any small variation in the temperature and/or unsteady pulling speed and melt convection, produce fluctuation in the growth rate leading to formation of so called swirls or striations [13]. Striations can be of different nature (e.g. due to doping or oxygen content) and in general, impurities, vacancies and interstitials produce complex micro-defects often distributed in a concentric or rings pattern. In this study, the effect of striations on the silicon solar cell performance and their recovery are investigated in details.

\section{Method}

A set of industrial scale $\mathrm{Cz}$ ingots have been produced in different furnaces and at different suppliers. The ingots are ntype doped and their specifications (resistivity and interstitial oxygen level (Oi)) are reported in Table 1.

The ingots have been cut into wafers according to the scheme in Fig. 1 and used for the manufacturing of n-type silicon solar cells.

For the fabrication of n-type solar cells from these wafers, a simplified version of the N-PASHA process [14] was used. The bifacial solar cell consists of a H-pattern screen print on each side of the solar cell. In addition, half-fabricates were manufactured to 
Table 1

Ingot description.

\begin{tabular}{lllll}
\hline $\begin{array}{l}\text { Ingot } \\
\text { designation }\end{array}$ & Description & Type & $\begin{array}{l}\text { Resistivity } \\
\text { level in the } \\
\text { top } \\
{[\mathrm{ohm} \times \mathrm{cm}]}\end{array}$ & $\begin{array}{l}\text { Oi level } \\
\text { (in the } \\
\text { top) } \\
\text { [ppma] }\end{array}$ \\
\hline A & Furnace A & n-Type & 5 & $<18$ \\
B & Furnace B & n-Type & 5 & $<18$ \\
C & Furnace C & n-Type & 5 & $<16$ \\
D & Furnace D & n-Type & 13 & $<20$ \\
E & Furnace E & n-Type & 8 & $<18$ \\
F & Furnace F & n-Type & 20 & $<18$ \\
\hline
\end{tabular}

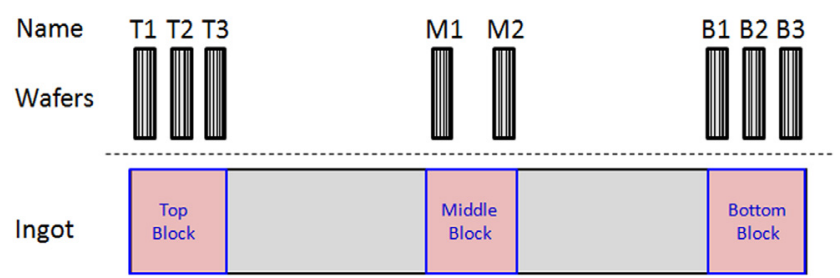

Fig. 1. Schematic of the ingot and sections used for the investigation.

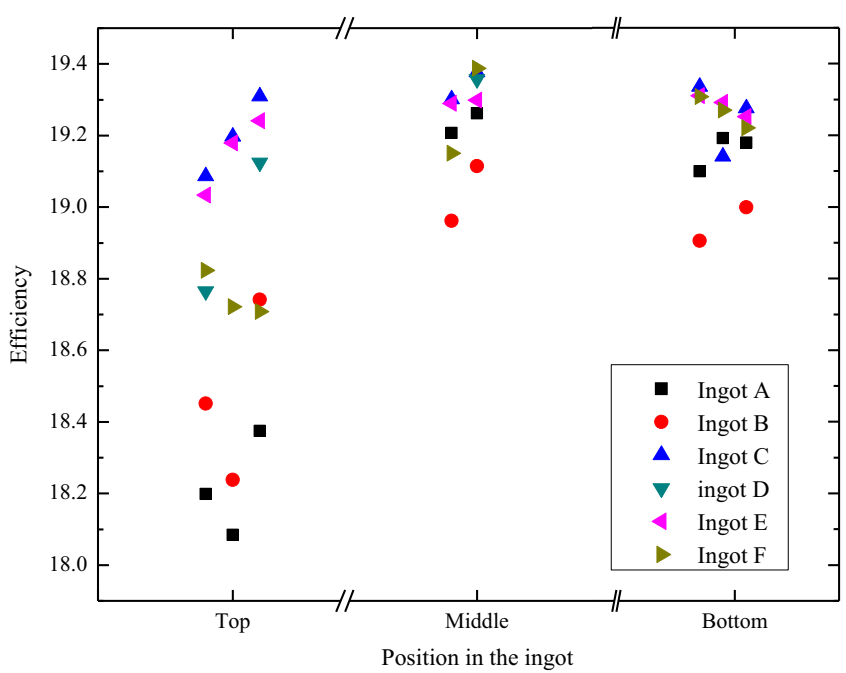

Fig. 2. Solar cell efficiency as function of position in the ingot (not in scale).

study the lifetime, using the same process of the solar cells excluding the metallization.

The solar cells results are reported in Fig. 2.

After characterization both the solar cells and the halffabricates were subjected to a $10 \mathrm{~min}$ anneal at $200{ }^{\circ} \mathrm{C}$ in air. This type of anneal is common practice for p-type solar cells to split the boron-oxygen complex responsible for light induced degradation. Prior to the anneal, the cells and wafers were stored at room temperature in the dark. The cells and wafers were analysed by current-voltage (IV) measurements, Internal Quantum Efficiency (IQE) measurements, Microwave Photo-Conductance Decay ( $\mu \mathrm{W}$ PCD), Light Beam Induced Current (LBIC), Electro-Luminescence (EL) and Photo-Luminescence (PL) measurements both prior and after the anneal.

\section{Results}

The solar cell performance throughout the ingot generally forms a flat curve along the ingot height. However, some ingots show a significant decrease of the efficiency in the really top with respect to the top (remainder of), middle and bottom regions. These solar cells exhibit an efficiency drop up to $1 \%$ abs with respect to cells from the middle of the same ingot (see Fig. 2). The size of the drop depends on the ingot characteristics (e.g. oxygen and phosphorous levels), and strong correlation was observed between the occurrence and size of the drop and the presence of striations in the wafer (see Fig. 6).

For the solar cells from the seed end a large improvement of the cell efficiency can be observed after the proposed annealing. For the cells from the centre of the ingot body the annealing step has hardly any effect on the cell efficiency (see Fig. 3a). For ingots A and $\mathrm{B}$, we observe that $J_{\mathrm{SC}}$ and $V_{\mathrm{OC}}$ improve significantly (see Fig. $3 b$ ). Ingot $C$ has also an efficiency increase which is almost entirely due to an increase in fill factor. A similar increase in fill factor is found also in the other two ingots A and B. The increase in fill factor for ingot $D$ is also present, but to a somewhat lesser degree. This increase in fill factor corresponds completely to an increase in pseudo-fill factor, which indicates that the improvement is not the result of a series resistance decrease, related, for example, to an improved metallisation. This is instead due to an increase in the homogeneity of the lateral lifetime distribution over the solar cells (see Fig. 6).

In lower quality ingots, not reported here, we observe even larger efficiency drop and a nearly equivalent recovery.

The effect of the annealing treatment is stable under $18 \mathrm{~h}$ illumination at 1 sun (see Fig. 4), which provides further evidence that the effect is not related to any $\mathrm{B}-\mathrm{O}$ complex formation. A higher temperature treatment at $600{ }^{\circ} \mathrm{C}$, which is about the highest temperature than can safely be applied to finished solar cells, gives neither further improvement, nor further degradation (see Fig. 4).

In order to understand the effect of the annealing, we carried out spectral response and reflectance measurements to calculate the IQE. In Fig. 5a the ratio of the IQE after and before annealing as a function of wavelength is compared for a solar cell from the centre and a cell from a position closer to the seed end of ingot A. For the cell from the middle of the ingot, this ratio is about 1 for the full spectrum since there is negligible change in the cell performance. The cell from the seed end of the ingot, however, displays a significant increase for wavelengths greater than $900 \mathrm{~nm}$, which is commonly related to an increase in bulk carrier lifetime. However the rear side passivation plays also a role at longer wavelength. In order to discern the bulk from the rear passivation we measure the IQE spectra from the rear side of these solar cells (see Fig. 5b). In a rear IQE graph, the short wavelength is representative for the surface passivation and the back surface field (BSF) quality and the remainder of the visible spectrum indicates the bulk quality. Results in Fig. 5 confirm that it is indeed the bulk quality and not the surface passivation at the rear side of the cell which improves due to the annealing step.

$\mu \mathrm{W}$-PCD maps were made of half-fabricates from the seed end of all ingots before and after the annealing treatment. An example of the resulting maps is shown in Fig. 6a and b. Also IQE maps acquired on neighbouring cells using the LBIC technique combined with local reflectance maps resulted in qualitatively similar images in which the rings disappeared.

The improvement in minority carrier lifetime is present over almost the entire wafer. Faint evidence of rings can be found after anneal for some wafers and usually disappear after a second annealing.

\subsection{Comparison to p-type rings}

Sometimes rings pattern are also observed in p-type ingot as mentioned earlier [15]. In another study [16] p-type solar cells 

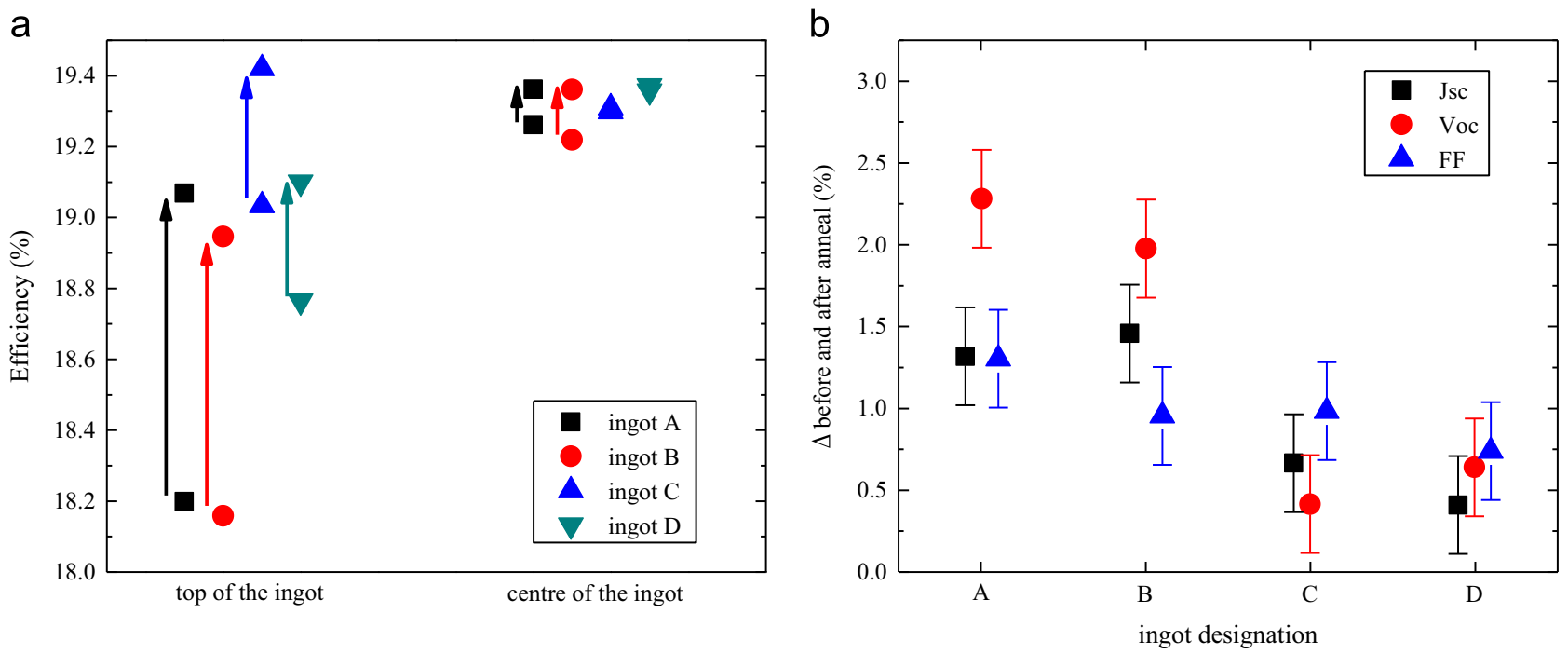

Fig. 3. (a) Efficiency recovery over the ingot after annealing. (b) Composition of efficiency recovery in cell parameters.

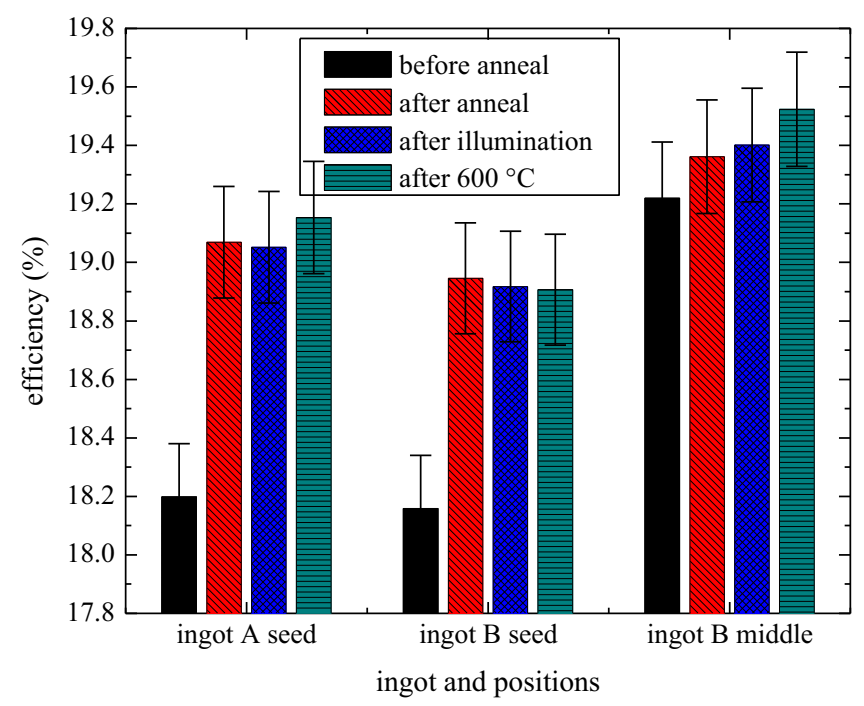

Fig. 4. The effect of further temperature and light treatments on ingot A and B.

were manufactured using a standard phosphorus emitter, Al BSF and $\mathrm{H}$-pattern screen print. Also in this case rings pattern have been observed. These cells were subject to the same $10 \mathrm{~min}$ anneal at $200{ }^{\circ} \mathrm{C}$.

The annealing treatment did not cause any improvement for p-type solar cells in which a similar ring pattern was observed by EL (Fig. 7a and b). Neither the rings disappeared nor the cell efficiency improved after this annealing. Indeed this cell was not subject to illumination before annealing therefore no B-O complex was present.

\section{Discussion}

In this experiment we discover the presence of a bulk defect strongly reducing the efficiency of n-type solar cells. It is localized near the seed side of n-type ingot (Fig. 1) and it is visible as low lifetime ring shape regions on solar cells (Fig. 6a). This defect is deactivated by a low temperature anneal at $200{ }^{\circ} \mathrm{C}$ for $10 \mathrm{~min}$. The main question is what type of defect is in agreement with such low de-activation temperature. In the following we will review different hypothesis on the nature of the striations with the intention to help the further microscopic investigation.

We also notice that not all the ingots are affected by these ring shape regions and by the reduced efficiency. In particular an ingot with less Oi concentration and similarly another ingot with lower doping level show no evidence of this type of bulk lifetime degradation. On the other side an ingot with even lower level of $\mathrm{P}$ does report, although only in a limited manner, striations sensitive to low $\mathrm{T}$ anneal. The relation of Oi with the formation of this defect is not clear yet. Also if and why phosphorous plays a role.

The n-type ingots were mostly grown from high quality feedstock, without any boron contamination. Therefore the only boron in the n-type solar cells and half-fabricates results from the emitter layer diffusion in the front side of the cell. In this highly doped layer, any detrimental effect of B-O complex formation can be considered negligible compared to the Auger recombination dominating the emitter region. Considering also the missing defect re-formation under illumination (see Fig. 4), we conclude that B-O pairs cannot be responsible of this degradation. Also we considered hydrogenation as a possible mechanism for the interpretation of this phenomenon. However according to the hydrogenation formulation as described in [22] and [23], this can be ruled out due to the opposite formation kinetics.

Although not much is known about the nature of these striations, oxygen is surely the first candidate since the seed side of the ingot is affected by high $\mathrm{O}$ concentration. However oxygen induced type of defects are formed or annealed at much higher temperature $[17,18,8,19,20]$. On the other hand, more recombination centre can be introduced when oxide precipitates are decorated by transitions metals as recently found for Fe in p-type by Murphy et al. [24] then the formation kinetics should also change.

In his studies Watkins [20] reported the existence of a vacancyphosphorus pair. This complex has a defect level at $0.43 \mathrm{eV}$ below the conduction band. In addition this pair is de-activated at temperature in the $100-200{ }^{\circ} \mathrm{C}$ range. Is this the type of defect responsible for the phenomena reported in this work? On one side this is supported by the finding that rings are not de-activated in p-type silicon wafers showing that the complex responsible must have a different nature. On the other side, Watkins itself in an earlier study reports that, in pulled crystals containing oxygen in the 2-20 ppma range, this defect is not observed [21] since the dominant defect is vacancy trapped by oxygen. Of course in the formation, the actual oxygen dissolved and precipitated has to be 

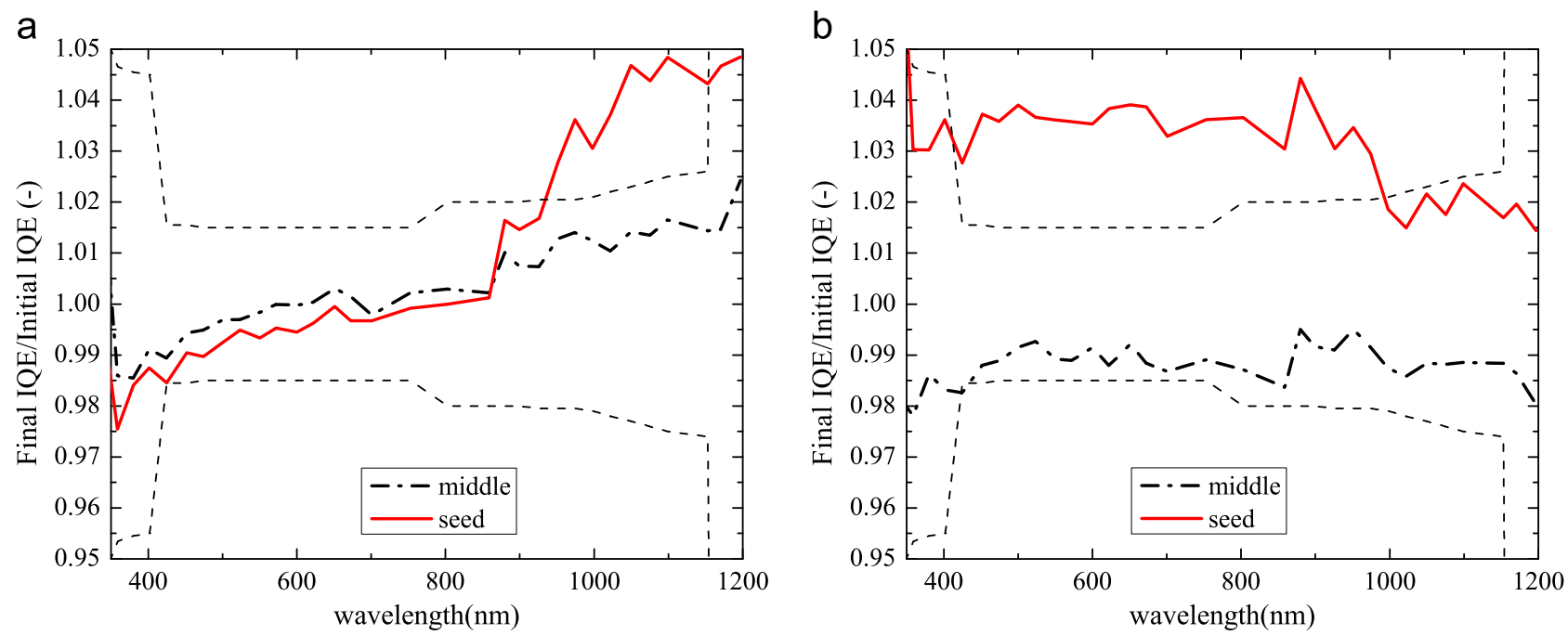

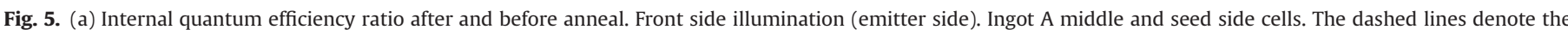
uncertainty in the measurement. (b) Internal quantum efficiency ratio of same cells in (a) using rear side illumination (BSF side).
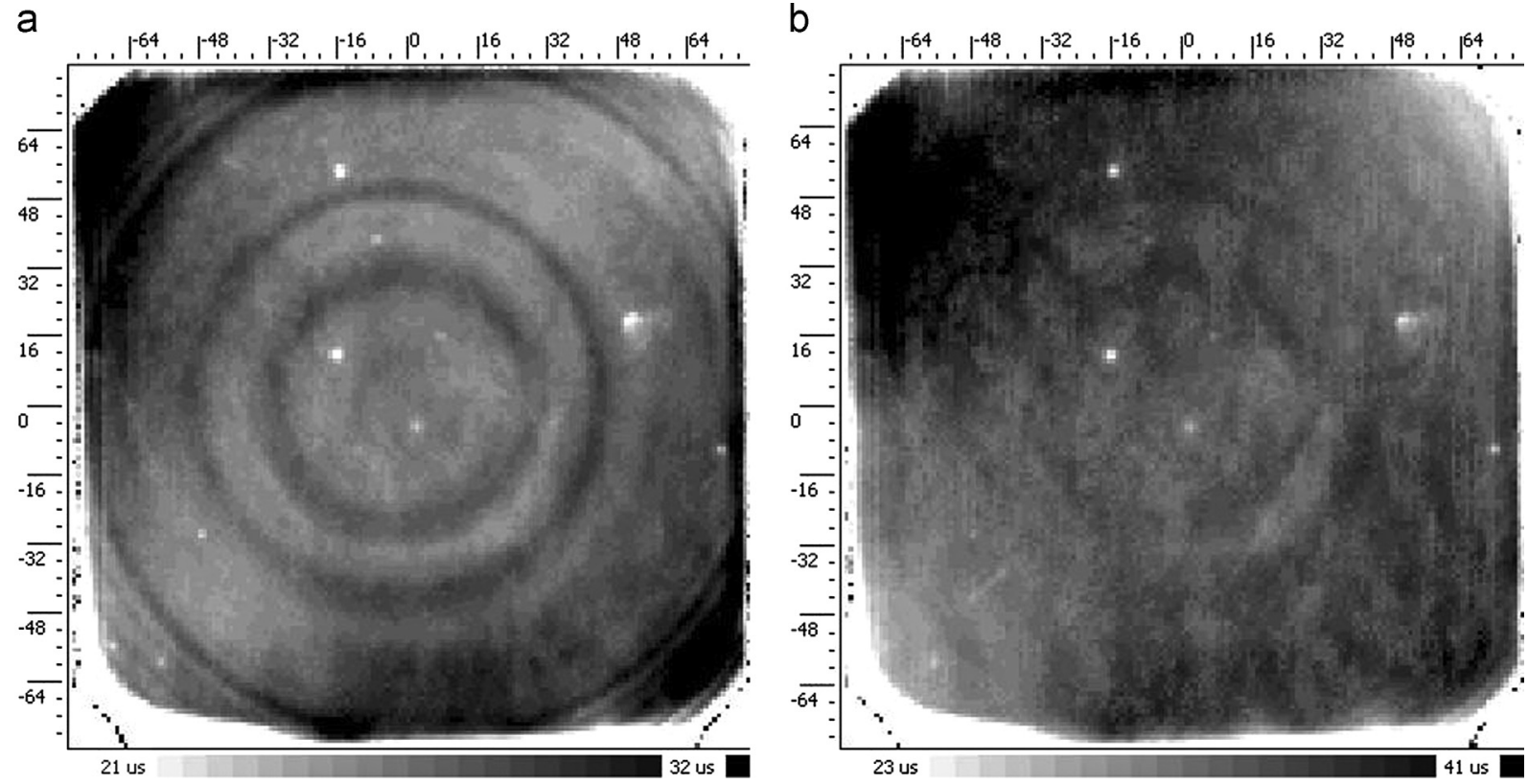

Fig. 6. (a) uPCD of half fabricate before anneal. (b) uPCD of half fabricate after anneal.

a

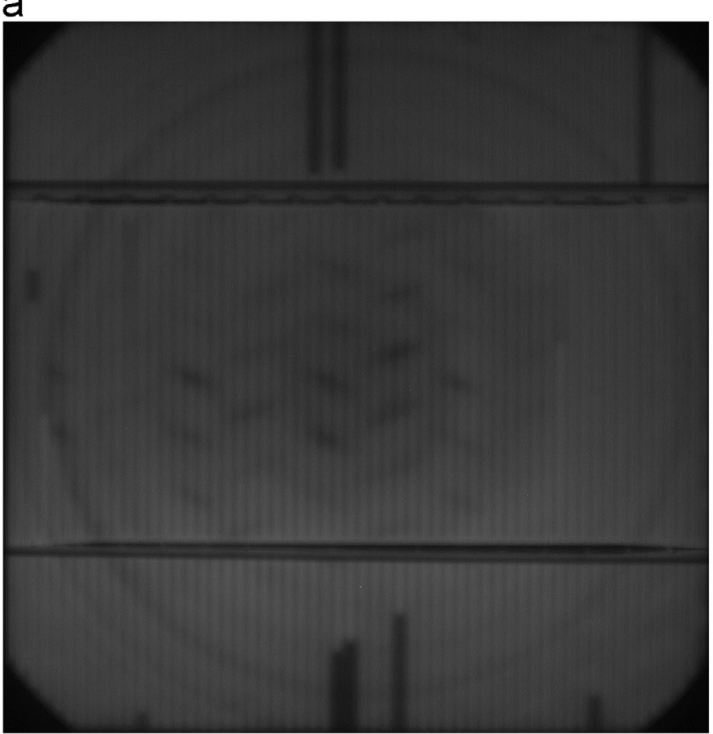

b

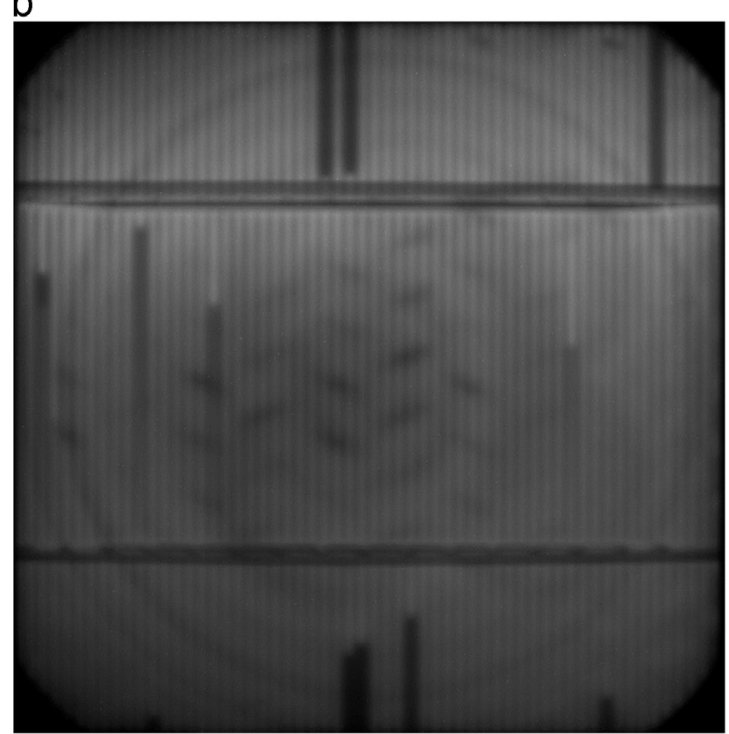

Fig. 7. (a) Electro-luminescence of p-type sample before anneal. (b) Electro-luminescence of p-type sample after anneal. 
considered. However since nothing is known about the carrier capture cross section of either $\mathrm{V}-\mathrm{P}$ or $\mathrm{V}-\mathrm{O}$, it is not possible at this stage to formulate their recombination properties and determine which one dominate the recombination even at low defect concentrations. The identification of the defect responsible for this phenomena requires further investigation on microscopic level.

\section{Conclusions}

A set of several industrial n-type ingots have been analysed on cell level. The efficiency distribution in the top, middle and tails of ingots is reported. The presence of striations for wafers near the outmost seed end of some $\mathrm{Cz}$ ingots reduces the solar cell performance. The impact on solar cell efficiency has been shown here to be up to $\sim 1 \%$ absolute with respect to cells from the middle region of the same ingots. In this work it is demonstrated that the striation patterns visible on solar cells can be fully eliminated by a simple anneal at $200{ }^{\circ} \mathrm{C}$. This recovery is stable in storage conditions, under illumination and high temperature treatments up to $600{ }^{\circ} \mathrm{C}$. The increase in both $V_{\mathrm{OC}}$ and $J_{\mathrm{SC}}$ is almost entirely related to an increase in the bulk lifetime, as confirmed by IQE measurements. The pseudo FF, and therefore the FF also increases, due to an increase in the homogeneity of the lateral lifetime distribution over the solar cells. The same recovery cannot be reproduced in p-type $\mathrm{Cz}$ silicon solar cells with similar ring shaped patterns. This suggests that the bulk defect that degrades the lifetime at the location of the striations is not identical for pand n-type wafers. Partially inspired by this, the formation of vacancy-phosphorous pairs is suggested in this contribution due to their low deactivation temperature and defect energy level in the band-gap. Although these defects identification requires more microscopic and fundamental studies, this result reported here can be considered a first step towards the understanding and the mitigation of the detrimental effect of striations in n-type solar cells.

\section{References}

[1] N.P.D. Solarbuzz, PV Equipment Quarterly Report, 〈http://www.solarbuzz.com/ $>$ (last accessed 22/11/2014)

[2] International Technology Roadmap for Photovoltaic (ITRPV), Results 2012, 〈http://www.itrpv.net/〉.

[3] S.W. Glunz, S. Rein, W. Warta, J. Knobloch, W. Wettling, On the degradation of Cz-silicon solar cells, in: Proceedings of the 2nd World Conference on Photovoltaic Energy Conversion, Vienna, Austria, July 1998, pp. 1343-1346.

[4] J. Schmidt, A.G. Aberle, R. Hezel, Investigation of carrier lifetime instabilities in Cz-grown silicon, in: Proceedings of the IEEE 26th Photovoltaic Specialists Conference (PVSC '97), Anaheim, California, USA, September-October 1997, pp. 13-18.
[5] D. Macdonald, L.J. Geerligs, Recombination activity of interstitial iron and other transition metal point defects in p- and n-type crystalline silicon, Appl. Phys. Lett. 85 (2004) 4061-4063.

[6] J.E. Cotter, J.H. Guo, P.J. Cousins, M.D. Abbott, F.W. Chen, K.C. Fisher, p-type vs. n-type silicon wafers: prospects for high-efficiency, commercial silicon solar cells, 15th Workshop on Crystalline Silicon Solar Cells \& Modules, 2005, p. 3.

[7] W.C. Dash, Growth of silicon crystals free from dislocations, J. Appl. Phys. 30 (1959) 459-474.

[8] R.C. Newman, Defects in silicon, Rep. Prog. Phys. 45 (1982) 1163-1210.

[9] Y. Hu, Characterization of Defects in N-type Cz Silicon for Solar Cells (PhD Thesis), Trondheim, October 2012.

[10] Zhou Chun-Lan, Wank Wen-Jing, Li Hai-Ling, Zhao Lei, Diao Hong-Wei, Li $\mathrm{Xu}$-Dong, Influence of ring oxidation-induced stack faults on efficiency in silicon solar cells, Chin. Phys. Lett. 25 (2008) 3005-3008.

[11] V.V. Voronkov, R. Falster, Vacancy type microdefect formation in Cz silicon, J. Cryst. Growth 194 (1998) 76-88.

[12] M. Juel, Y. Hu, V.S. Koien, M. Jomâa, S. Zhang, E. Øvrelid, The influence of growth rate variations on defect formation in CZ-silicon, in: Proceedings of the 6th International workshop on Crystalline Silicon for Solar Cells, Aix-les-bains, France, October 8-11, 2012

[13] S. Kasap, P. Capper, Springer Handbook of Electronic and Photonic Materials, vol. 13, 2007, pp. 255-269.

[14] I.G. Romijn, B.B. Van Aken, J. Anker, A.R. Burgers, A. Gutjahr, B. Heurtault, M. Koppes, E. Kossen, M. Lamers, D.S. Saynova, C.J.J. Tool, F. Lang, G. Li, H. Wang, Z. Hu, P.R. Venema, A.H.G. Vlooswijk, Industrial implementation of efficiency improvements in n-type solar cells and modules, in: Proceedings of the 27th Europen Photovoltaic Solar energy Conference and Exhibition, Frankfurt, Germany, October 2013, pp. 533-537.

[15] J. Haunschild, J. Broisch, I.E. Reis, S. Rein, Quality control of Czochralski grown silicon wafers in solar cell production using photoluminescence imaging, in: Proceedings of the 26th EUPVSEC, Hamburg, Germany, September 2011, pp. 1025-1031.

[16] P.C.P. Bronsveld, P. Manshanden, F.O. Lenzmann, Ø. Gjerstad, E.J. Øvrelid, Recycling of p-type mc-Si top cuts into p-type mono c-Si solar cells, Energy Procedia 38 (2013) 536-541.

[17] R.J. Falster, M. Cornara, D. Gambaro, M. Olmo, M. Pagani, Effect of high temperature pre-anneal on oxygen precipitates nucleation kinetics in Si, Solid State Phenom. 57-58 (2007) 123-128.

[18] D.C. Walter, B. Lim, R. Falster, J. Binns, J. Schmidt, Understanding lifetime degradation in Czochralski-grown n-type silicon after high-temperature processing, in: Proceedings of the 28th Europen Photovoltaic Solar Energy Conference and Exhibition, Paris, France, October 2013.

[19] K.F. Kelton, R. Falster, D. Gambaro, M. Olmo, M. Cornara, P.F. Wei, Oxygen precipitation in silicon: experimental studies and theoretical investigations within the classical theory of nucleation, J. Appl. Phys. 85 (1999) 8097-8111.

[20] G.D. Watkins, Influence of ring oxidation-induced stack faults on efficiency in silicon solar cells, Mater. Sci. Semicond. Process. 3 (2000) 227-235.

[21] G.D. Watkins, J.W. Corbett, Defects in irradiated silicon: electron paramagnetic resonance and electron-nuclear double resonance of the Si-E center, Phys. Rev. 134 (1964) A1359-1377.

[22] A. Herguth, G. Schubert, M. Kaes and G. Hahn, Avoiding boron-oxygen related degradation in highly boron doped $\mathrm{Cz}$ silicon, in: Proceedings of the 21st Europen Photovoltaic Solar energyEnergy Conference and Exhibition, Dresden, Germany, September 2006.

[23] B.J. Hallam, P.G. Hamer, S.R. Wenham, M.D. Abbott, A. Sugianto, A.M. Wenham, C.E. Chan, G.Q. Xu, J. Kraiem, J. Degoulange, and R. Einhaus, Advanced bulk defect passivation for silicon solar cells, Photovoltaics, IEEE Journal of 4, 2014, 88-95 and reference therein.

[24] J.D. Murphy, K. Bothe, V.V. Voronkov, R.J. Falster, On the mechanism of recombination at oxide precipitates in silicon, Applied Physics Letters 102 (2013) 042105 